\title{
Effect of propofol on hepatic blood flow and oxygen balance in rabbits
}

\author{
[L'effet du propofol sur le débit sanguin et l'équilibre d'oxygène hépatiques chez le \\ lapin]
}

Tao Zhu MD, ${ }^{*}$ Qiying Pang MD, ${ }^{*}$ Stuart A. McCluskey MD PhD, $†$ Chaozhi Luo MD*

Purpose: Propofol has been reported to alter hepatic blood flow and to increase hepatic oxygen consumption. This study was designed to determine the effect of propofol on hepatic blood flow and oxygenation in rabbits, in order to establish its net effect on hepatic oxygen balance.

Methods: Twenty, adult male, New Zealand white rabbits were randomly divided into two groups: Group P (propofol, 0.6 $\left.\mathrm{mg} \cdot \mathrm{kg}^{-1} \cdot \mathrm{min}^{-1}\right)$ or Group C (10\% intralipid, $\left.0.6 \mathrm{mg} \cdot \mathrm{kg}^{-1} \cdot \mathrm{min}^{-1}\right)$. An electromagnetic flowmeter was used to measure hepatic blood flow, and blood, from the carotid artery, the portal vein, and the hepatic vein, was used to determine hepatic oxygenation. After we obtained baseline values, we repeated measurements ten, 30, and $60 \mathrm{~min}$ after initiating the infusion.

Results: Intralipid did not affect systemic hemodynamics, hepatic blood flow, or oxygenation during the 60 min infusion; however, propofol caused a time-dependent decrease in mean arterial blood pressures and an increase in portal venous flow and total hepatic blood flow. In contrast, hepatic arterial blood flow remained unchanged during the propofol infusion. Hepatic oxygen delivery and consumption increased in a time-dependent manner to maximums of $25 \%$ and $21.4 \%$ (both, $P<0.05$ ) above baseline, respectively. Hepatic venous oxygen saturation and extraction was unchanged throughout the study period.

Conclusion: Propofol increases total hepatic blood flow, primarily by increasing hepatic portal venous flow. The increase in liver oxygen consumption was fully compensated by an increase in oxygen supply to the liver, resulting in a preserved, hepatic oxygen balance.

CAN J ANESTH $2008 / 55: 6 / 364-370$
Objectif : Il a été signalé que le propofol modifie le débit sanguin hépatique et augmente la consommation hépatique d'oxygène. Cette étude $a$ été conçue dans le but de déterminer l'effet du propofol sur le débit sanguin hépatique et l'oxygénation chez le lapin afin d'évaluer son effet net sur l'équilibre de l'oxygène hépatique.

Méthode: Vingt lapins blancs de Nouvelle-Zélande, des mâles adultes, ont été randomisés en deux groupes: le groupe $P$ (propofol, 0,6 $\left.\mathrm{mg} \cdot \mathrm{kg}^{-1} \cdot \mathrm{min}^{-1}\right)$ ou groupe C (10\% Intralipide, $\left.0,6 \mathrm{mg} \cdot \mathrm{kg}^{-1} \cdot \mathrm{min}^{-1}\right)$. Un débitmètre électromagnétique $a$ été utilisé pour mesurer le débit sanguin hépatique, et le sang provenant de l'artère carotide, de la veine porte et de la veine sus-hépatique a été utilisé pour déterminer l'oxygénation hépatique. Après avoir obtenu des valeurs de base, nous avons répété les mesures 10,30 et 60 minutes après le début de la perfusion.

Résultats : L'Intralipide n'a pas eu d'effet sur l'hémodynamie, le débit sanguin hépatique ou l'oxygénation pendant la perfusion de 60 minutes ; néanmoins, le propofol a provoqué une réduction à dépendance chronologique dans les pressions artérielles moyennes et une augmentation du débit veineux porte et du débit sanguin hépatique total. En revanche, le débit sanguin de l'artère hépatique est demeuré constant pendant la perfusion de propofol. L'apport et la consommation d'oxygène hépatique ont augmenté de façon chronologiquement dépendante à des maximums de $25 \%$ et $21,4 \%$ $(P<0,05$ pour les deux) au dessus des taux de base, respectivement. La saturation et l'extraction d'oxygène de la veine sus-hépatique sont demeurées constantes tout au long de la période à l'étude.

Conclusion: Le propofol augmente le débit sanguin hépatique total principalement en augmentant le débit de la veine porte vers le foie. L'augmentation de la consommation d'oxygène hépatique a été complètement compensée par une augmentation de l'apport d'oxygène au foie, avec pour résultat un équilibre d'oxygène hépatique conservé.

From the Department of Anesthesiology, ${ }^{*}$ West China Hospital, Sichuan University, Chengdu, Sichuan, China; and the Department of Anesthesia and Pain Management, $†$ Toronto General Hospital, University of Toronto, Toronto, Ontario, Canada.

Address correspondence to: Dr. Chaozhi Luo, Department of Anesthesiology, West China Hospital, Sichuan University, Chengdu

Sichuan Province, 610041, China. Phone: 86-28-85423593; Fax: 86-28-85423591; E-mail: xwtao_zhu@yahoo.com

Accepted for publication October 25, 2007.

Revision accepted February 14, 2008.

Final revision accepted March 6, 2008. 
$\mathrm{P}$ ROPOFOL (2,6-dissopropyl phenol), a rapid acting intravenous anesthetic agent, has been widely used for the induction and maintenance of general anesthesia. Its short duration of action is due to a high total body clearance, due, in part, to rapid and extensive hepatic clearance. The result of propofol's rapid hepatic metabolism is an increase in oxygen consumption $\left(\mathrm{hVO}_{2}\right) .{ }^{1}$ In addition, propofol anesthesia produces hypotension and peripheral vasodilatation, which may affect the hepatic blood flow and, accordingly, hepatic oxygen delivery $\left(\mathrm{hDO}_{2}\right){ }^{2}$ Therefore, we hypothesized that propofol may reduce net oxygen supply to the liver, due to increased oxygen utilization through it own metabolism, and may reduce hepatic blood flow, due to systemic hypotension.

In hepatobiliary surgery, the liver is susceptible to ischemic injury; therefore, it is important to determine the effects of propofol on hepatic blood flow and the balance between $\mathrm{hDO}_{2}$ and consumption. There are a limited number of animal studies on the effect of propofol on hepatic blood flow and hepatic oxygen balance, and the results of these studies are equivocal. ${ }^{1,3-8}$ Furthermore, the techniques used to monitor the hepatic blood flow were indirect measurements, with methodological limitations requiring interpretation of the results. ${ }^{7,9-11}$ Although there are some limitations for the electromagnetic technique, this direct measurement of hepatic blood flow is considered to be an accurate method of measuring blood flow within vessels., ${ }^{9}, 11$ The current study, using electromagnetic flowmeters, was designed to examine the effect of propofol on hepatic blood flow and on hepatic oxygenation, in order to establish its net effect on hepatic oxygen balance.

\section{Methods}

\section{Study animals}

Mature, male, New Zealand white rabbits (2.1-2.4 $\mathrm{kg}$ ) were studied with the approval of the Institute for Animal Use Committee of Sichuan University. The animals were housed in environmentally controlled units and they fasted for $12 \mathrm{hr}$ prior to the study. Animals with an abnormal body temperature or a recent (two months) history of exposure to any medication were excluded. We used the software (Package for Encyclopaedia of Medical Statistics 3.1 for Windows) developed by our university to generate randomization.

\section{Study medication}

We studied the hepatic hemodynamics of propofol, a highly lipid, soluble medication, and its solvent, intralipid. Propofol and Intralipid $\AA$ were supplied by AstraZeneca-China Ltd. (AstraZeneca, Shanghai, China) and Sino-Swed Pharmaceutical Corp. Ltd., Wuxi, China, respectively. Study solutions were prepared by a research assistant not directly involved in the surgical protocol. Participants in the study protocol and data analysis were blinded to the group allocation, which was revealed after the data analysis was completed.

\section{Anesthesia and monitoring}

All of the rabbits were anesthetized with ketamine (30 $\left.\mathrm{mg} \cdot \mathrm{kg}^{-1} \mathrm{im}\right)$, and anesthesia was maintained with $1.5 \%$ sodium pentobarbital $\left(30 \mathrm{mg} \cdot \mathrm{kg}^{-1}\right)$ infused via the marginal ear vein. A tracheotomy was performed and intratracheal intubation was established. The animals were ventilated with a volume-controlled, animal ventilator (DH-140, Medical Instrument Corporation of Zhejiang University, Zhejiang, China). Their respiratory rate, tidal volume, and inspired oxygen fraction were adjusted to maintain arterial, carbon dioxide tension between 35 and $40 \mathrm{mmHg}$ and arterial, oxygen partial pressure between 90 and $100 \mathrm{mmHg}$.

The right carotid artery and the jugular vein were cannulated to monitor arterial blood pressure and central venous pressure, respectively. Both catheters were connected to pressure transducers, and signals were recorded online (RM-6000, Nihon Kohden, Tokyo, Japan; Analysis and Archive systems, Powerlab ${ }$, ADInstruments Pty Ltd., Castle Hill, Australia). A warming table was used to maintain the body temperature of the animals at $38-39^{\circ} \mathrm{C}$, and the electrocardiogram, urinary volume, and rectal temperature were monitored throughout the surgical procedure.

\section{Surgical procedure}

A median laparotomy was performed for liver exposure. The portal vein and hepatic artery were isolated by blunt dissection. Two pre-calibrated, electromagnetic, flow probes (MFV-3200, Nihon Kohden, Tokyo, Japan), of appropriate sizes to ensure a snug fit, were placed around the hepatic artery and the portal vein, as described previously. ${ }^{12}$ These flowmeters were used to monitor the portal venous blood flow (PvBF) and the hepatic arterial blood flow ( $\mathrm{HaBF})$. Care was taken to preserve the perivascular nerve plexus. Non-occlusive, zero flow readings were repeated during the experiment.

A $1-\mathrm{cm}$ groin incision was made and the femoral vein was isolated. Next, a catheter was advanced to the hepatic vein via the isolated femoral vein. Similarly, by way of the laparotomy, a branch of the mesenteric vein was isolated and then cannulated by direct puncture. 
TABLE General information and arterial blood gas analysis in the two groups

\begin{tabular}{|c|c|c|c|c|c|c|c|c|}
\hline \multirow{2}{*}{ Variable } & \multicolumn{4}{|c|}{ Group C } & \multicolumn{4}{|c|}{ Group P } \\
\hline & $t_{0}$ & $t_{10}$ & $t_{30}$ & $t_{60}$ & $t_{0}$ & $t_{10}$ & $\mathrm{t}_{30}$ & $t_{60}$ \\
\hline Weight (kg) & \multicolumn{4}{|c|}{$2.24 \pm 0.04$} & \multicolumn{4}{|c|}{$2.22 \pm 0.03$} \\
\hline Surgical duration $(\min )$ & \multicolumn{4}{|c|}{$150.9 \pm 5.0$} & \multicolumn{4}{|c|}{$151.1 \pm 5.8$} \\
\hline Blood loss $(\mathrm{mL})$ & \multicolumn{4}{|c|}{$15.5 \pm 2.2$} & \multicolumn{4}{|c|}{$15.6 \pm 1.3$} \\
\hline Fluid intake $(\mathrm{mL})$ & \multicolumn{4}{|c|}{$55.8 \pm 1.7$} & \multicolumn{4}{|c|}{$56.1 \pm 2.0$} \\
\hline Urine output (mL) & \multicolumn{4}{|c|}{$18.3 \pm 1.6$} & \multicolumn{4}{|c|}{$17.6 \pm 2.0$} \\
\hline $\mathrm{Hb}\left(\mathrm{g} \cdot \mathrm{dL} \mathrm{L}^{-1}\right)$ & $12.1 \pm 1.2$ & $12.1 \pm 1.2$ & $12.1 \pm 1.2$ & $12.1 \pm 1.2$ & $12.3 \pm 1.5$ & $12.3 \pm 1.5$ & $12.3 \pm 1.5$ & $12.2 \pm 1.5$ \\
\hline $\mathrm{PaO}_{2}(\mathrm{mmHg})$ & $96.6 \pm 3.0$ & $95.3 \pm 2.0$ & $94.5 \pm 3.1$ & $97.0 \pm 2.8$ & $96.1 \pm 3.6$ & $94.6 \pm 2.8$ & $95.9 \pm 2.2$ & $95.3 \pm 2.9$ \\
\hline $\mathrm{PaCO}_{2}(\mathrm{mmHg})$ & $35.7 \pm 2.3$ & $35.5 \pm 2.6$ & $35.3 \pm 2.7$ & $35.5 \pm 3.0$ & $36.1 \pm 2.0$ & $35.6 \pm 2.7$ & $35.4 \pm 2.9$ & $35.3 \pm 2.8$ \\
\hline $\mathrm{pH}$ & $7.43 \pm 0.04$ & $7.42 \pm 0.05$ & $7.42 \pm 0.04$ & $7.41 \pm 0.05$ & $7.42 \pm 0.04$ & $7.43 \pm 0.04$ & $7.43 \pm 0.05$ & $7.43 \pm 0.06$ \\
\hline Body temperature $\left({ }^{\circ} \mathrm{C}\right)$ & $39.0 \pm 0.5$ & $38.7 \pm 0.8$ & $38.7 \pm 0.6$ & $38.5 \pm 0.6$ & $39.0 \pm 0.5$ & $38.9 \pm 0.5$ & $38.8 \pm 0.6$ & $38.5 \pm 0.6$ \\
\hline
\end{tabular}

Data are mean $\pm \mathrm{SD}$. $\mathrm{Hb}=$ hemoglobin concentration; $\mathrm{PaO}_{2}=$ arterial oxygen partial pressure; $\mathrm{PaCO}_{2}=$ arterial carbon dioxide partial pressure. There were no significant differences between groups and measurement points.

After that, the cannula was advanced to the portal vein. The free flow of blood was assessed using a syringe. Using these two catheters, blood was sampled from the hepatic vein and from the portal vein, respectively.

Normovolemia was maintained with an infusion of crystalloid and colloid (normal saline: gelofusion $=$ 1:1; Gelofusion ${ }^{\circledR}$ B.Braun Biotech International, Melsungen, Germany), in order to keep the central venous pressure within $2 \mathrm{mmHg}$ of pressure at the start of the procedure (infusion rate of 5-8 $\left.\mathrm{mL} \cdot \mathrm{kg}^{-1} \cdot \mathrm{hr}^{-1}\right)$.

\section{Experimental design}

At the end of the surgical preparation, the animals were allowed $30 \mathrm{~min}$ for the hemodynamics to stabilize before baseline measurements were obtained $\left(t_{0}\right)$. After that, the animals were randomly given either propofol (Group P, $0.6 \mathrm{mg} \cdot \mathrm{kg}^{-1} \cdot \mathrm{min}^{-1}, n=10$ ) or $10 \%$ intralipid (Group C, $0.6 \mathrm{mg} \cdot \mathrm{kg}^{-1} \cdot \mathrm{min}^{-1}, n=10$ ). The infusion rate was based on previous studies., ${ }^{4,8}$ Measurements in both groups were repeated ten minutes $\left(\mathrm{t}_{10}\right), 30 \mathrm{~min}\left(\mathrm{t}_{30}\right)$, and $60 \mathrm{~min}\left(\mathrm{t}_{60}\right)$ after initiation of the infusion. At the same time, the blood samples $\left(0.5 \mathrm{~mL}\right.$ each) for the blood gas analysis (I-Stat ${ }^{\circledR}$, I-Stat Corporation, East Windsor, NJ, USA) were obtained from the right carotid artery, the portal vein, and the hepatic vein.

Equations for derived variables, total hepatic blood flow (HBF), $\mathrm{hDO}_{2}, \mathrm{hVO}_{2}$ and hepatic oxygen extraction $\left(\mathrm{ERO}_{2}\right)$ are listed in the Appendix.

\section{Statistical analysis}

Based on earlier work, the standard deviations of HBF and $\mathrm{hVO}_{2}$ as per our previous study in rabbits, were
$1.2 \mathrm{~mL} \cdot \mathrm{min}^{-1} \cdot \mathrm{kg}^{-1}$ and $0.2 \mathrm{~mL} \cdot \mathrm{min}^{-1} \cdot \mathrm{kg}^{-1}$, respectively. The $\alpha$ error was set at 0.05 (two-sided), and the type II error was set at 0.2. Based on this assumption, a minimum of six rabbits per group was required. Based on previous studies using rats and $\operatorname{dogs}^{4,8}$ ten rabbits per group would facilitate delivery of valid and credible results.

Statistical analyses were performed using SPSS 13.0 for windows (SPSS Inc., Chicago, IL, USA). Normal distribution of the data was determined by a P-P graph. Systemic hemodynamics, hepatic blood flow rates, and $\mathrm{ERO}_{2}$ ratios were compared using repeated measures analysis of variance. Where differences were identified, we used multiple $t$ test comparisons, with Bonferroni correction, to identify intragroup variations as a function of time, and we used paired $t$ tests to analyze the intergroup differences. Comparison of surgical duration and fluid balance between groups was performed by an independent samples $t$ test. Data are reported as mean \pm SD. $P$ values less than 0.05 were considered significant.

\section{Results}

The groups were similar with respect to body weight, surgical duration, fluid balance, and arterial blood gas results (Table). During the $60 \mathrm{~min}$ infusion (Figures 1-3), intralipid had no effect on systemic hemodynamics, hepatic blood flow, or hepatic oxygenation.

\section{Effect of propofol infusion on systemic hemodynamics} (Figure 1)

Both groups were comparable with respect to the baseline values $\left(t_{0}\right)$. Compared to Group C, propofol had no effect on systemic hemodynamics, with the exception that, after initiation of propofol infu- 

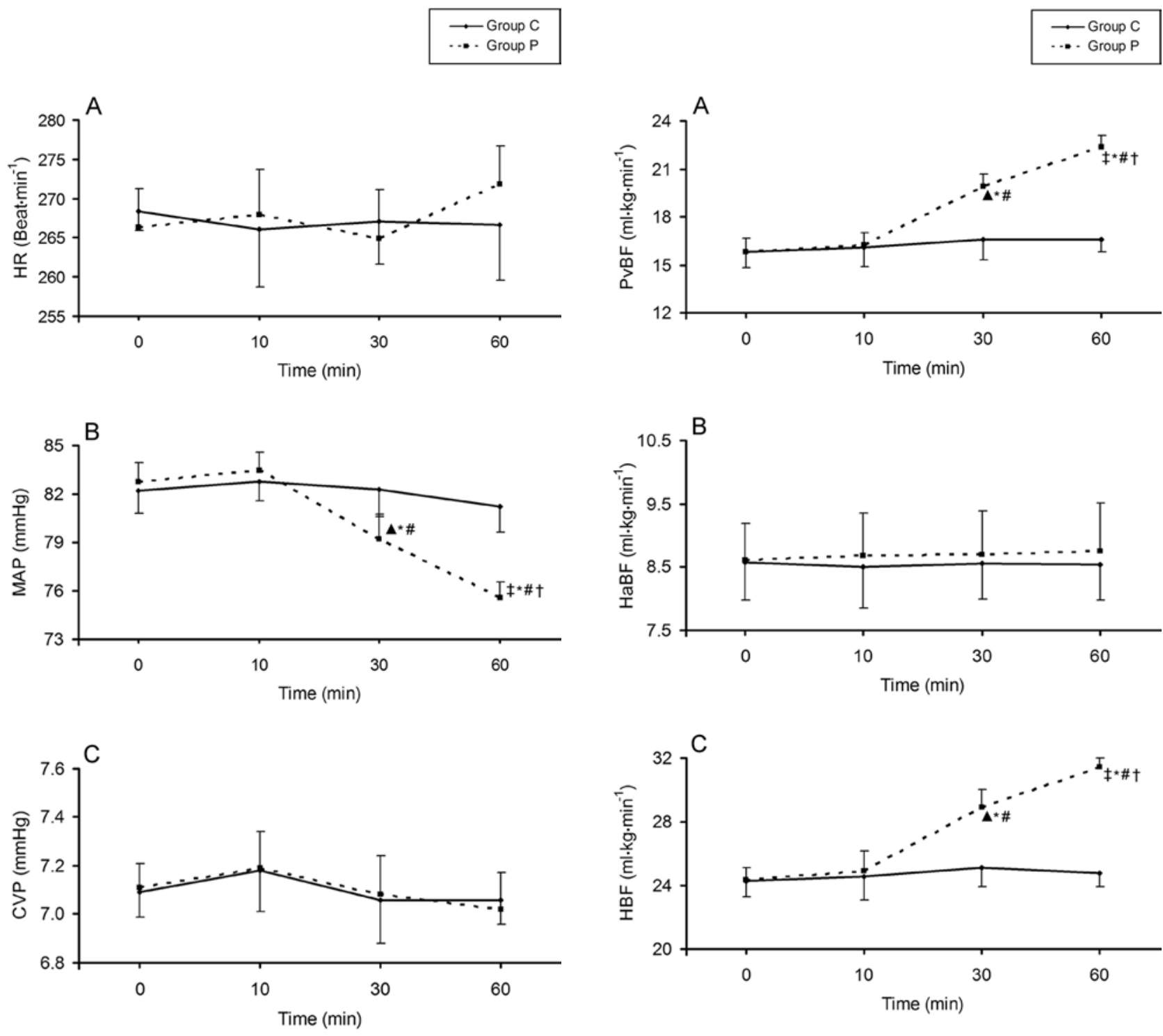

FIGURE 1 Time course of the effect of propofol infusion on systemic hemodynamics. Values are measured before propofol infusion $\left(\mathrm{t}_{0}\right)$ and after $10 \min \left(\mathrm{t}_{10}\right), 30 \mathrm{~min}\left(\mathrm{t}_{30}\right)$, and $60 \min \left(\mathrm{t}_{60}\right)$ of propofol infusion. Values represent mean \pm SD. $\boldsymbol{\Delta} P<0.05$ vs $\mathrm{t}_{30}$ in the Group C; $¥ P<0.05$ vs $\mathrm{t}_{60}$ in the Group $\mathrm{C} ;{ }^{*} P<0.05$ vs $\mathrm{t}_{0}$ in the Group P; $\# P<0.05$ vs $\mathrm{t}_{10}$ in the Group P; $† P<0.05$ vs $t_{30}$ in the Group P. HR = heart rate; $M A P=$ mean arterial blood pressure; $\mathrm{CVP}=$ central venous pressure.

sion, mean arterial blood pressure decreased to 79.2 $(P<0.001)$ and $75.6 \mathrm{mmHg}(P<0.001)$ at 30 and $60 \mathrm{~min}$, respectively. Otherwise, propofol markedly decreased mean arterial blood pressure with the time (Figure 1B).

FIGURE 2 Time course of the effect of propofol infusion on hepatic blood flow. Values are measured before propofol infusion $\left(\mathrm{t}_{0}\right)$ and after $10 \min \left(\mathrm{t}_{10}\right), 30 \min \left(\mathrm{t}_{30}\right)$, and $60 \min \left(\mathrm{t}_{60}\right)$ of propofol infusion. Values represent mean $\pm \mathrm{SD} . \Delta P<0.05$ vs $\mathrm{t}_{30}$ in the Group $C ; \ddagger P<0.05$ vs $\mathrm{t}_{60}$ in the Group $\mathrm{C} ;{ }^{*} P<0.05 v s \mathrm{t}_{0}$ in the Group P; $\# P<0.05$ vs $\mathrm{t}_{10}$ in the Group $P ; \dagger P<0.05 v s \mathrm{t}_{30}$ in the Group $\mathrm{P} . \mathrm{PvBF}=$ portal venous blood flow; $\mathrm{HaBF}=$ hepatic arterial blood flow; $\mathrm{HBF}=$ total hepatic blood flow.

Effect of propofol infusion on hepatic blood flow (Figure 2)

Basal hepatic blood flow and $\mathrm{PvBF}$ values were $24.3 \pm 0.8$ and $15.8 \pm 0.9 \mathrm{~mL} \cdot \mathrm{min}^{-1} \cdot \mathrm{kg}^{-1}$, respectively, which were comparable between groups (Figures $2 \mathrm{~A}$ and $2 \mathrm{C}$ ). During the $60 \mathrm{~min}$ infusion of propofol, 

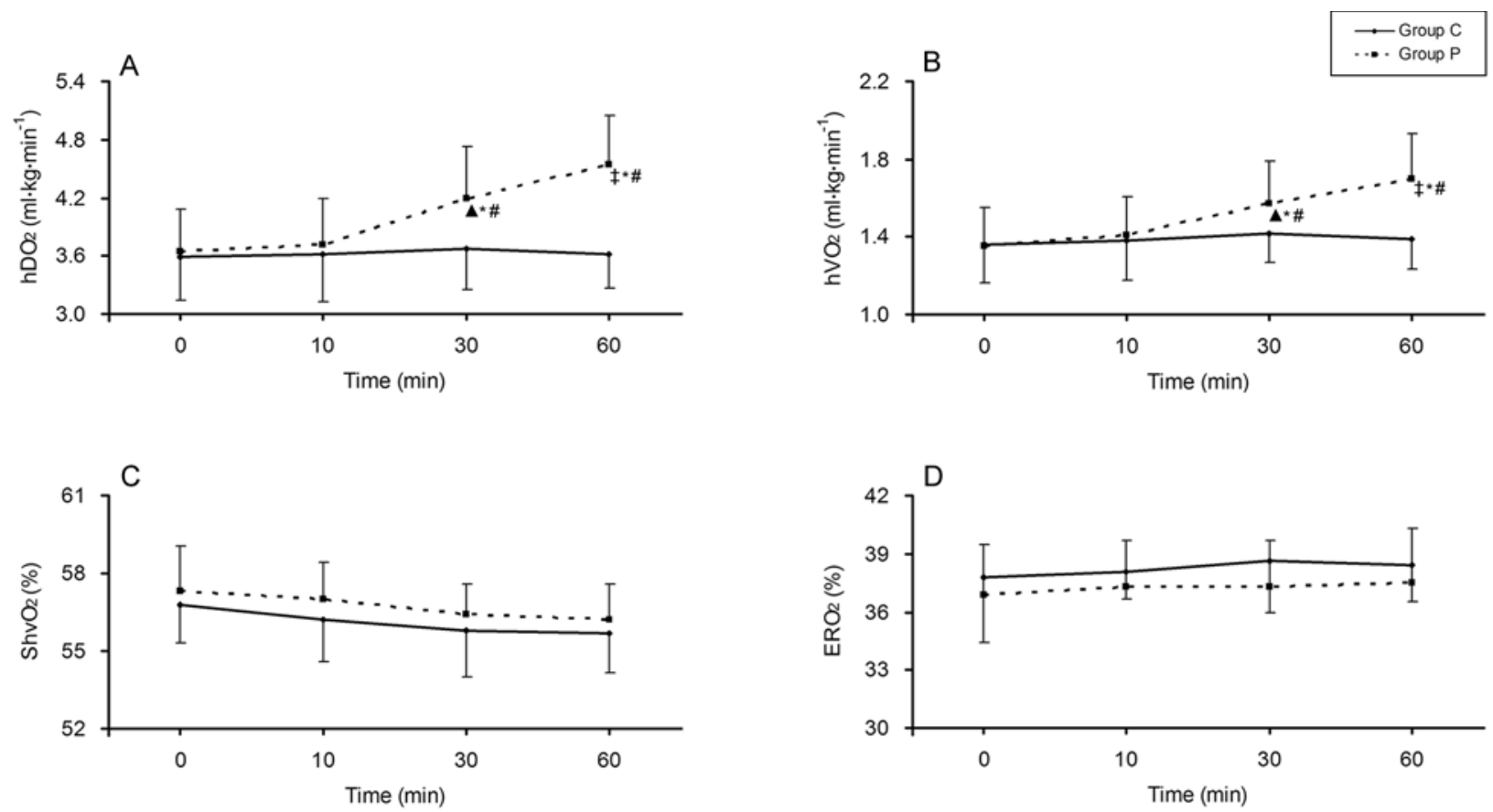

FIGURE 3 Time course of the effect of propofol infusion on hepatic oxygenation. Values are measured before propofol infusion $\left(\mathrm{t}_{0}\right)$ and after $10 \mathrm{~min}\left(\mathrm{t}_{10}\right), 30 \mathrm{~min}\left(\mathrm{t}_{30}\right)$, and $60 \mathrm{~min}\left(\mathrm{t}_{60}\right)$ of propofol infusion. Values represent mean $\pm \mathrm{SD}$. $\boldsymbol{\Delta} P<0.05$ vs $\mathrm{t}_{30}$ in the Group C; $\ddagger P<0.05 v s \mathrm{t}_{60}$ in the Group C; ${ }^{*} P<0.05 v s \mathrm{t}_{0}$ in the Group $\mathrm{P} ; \# P<0.05 v s \mathrm{t}_{10}$ in the Group $\mathrm{P} . \mathrm{hDO}_{2}=$ total hepatic oxygen delivery; $\mathrm{hVO}_{2}=$ total hepatic oxygen consumption; $\mathrm{ShvO}_{2}=$ hemoglobin oxygen saturation in hepatic vein; $\mathrm{ERO}_{2}=$ hepatic oxygen extraction ratio.

HBF and PvBF were higher compared to Group C, at $30 \mathrm{~min}$ (both, $P<0.001$ ) and at $60 \mathrm{~min}$ (both, $P$ $<0.001)$, after initiation of infusion. HBF and PvBF increased, over time, to $31.5 \pm 0.6(P<0.001)$ and $22.4 \pm 0.7 \mathrm{~mL} \cdot \mathrm{min}^{-1} \cdot \mathrm{kg}^{-1}(P<0.001)$, respectively (Figures 2A and 2C). However, HaBF was not affected by propofol infusion at any measured point during the infusion (Figure 2B).

\section{Effect of propofol infusion on hepatic oxygenation} (Figure 3)

The baseline values of $\mathrm{hDO}_{2}$ and $\mathrm{hVO}_{2}$ were comparable between the two groups (Figures $3 \mathrm{~A}$ and $3 \mathrm{~B}$ ). After initiation of the infusion, propofol increased hepatic oxygen delivery at $30 \mathrm{~min}(P=0.028)$ and at $60 \mathrm{~min}(P<0.001)$, compared to Group C (Figure 3A). Moreover, during propofol infusion, $\mathrm{hDO}_{2}$ increased over time from $3.6 \pm 0.4$ to $4.5 \pm 0.5$ $\mathrm{mL} \cdot \mathrm{min}^{-1} \cdot \mathrm{kg}^{-1}(P<0.001)$.

Compared to Group C, propofol also increased $\mathrm{hVO}_{2}$ at $30 \mathrm{~min}(P=0.043)$ and at $60 \mathrm{~min}(P=$ 0.002 ), after initiation of the infusion (Figure $3 \mathrm{~B}$ ). With time, during propofol infusion, hepatic oxygen consumption increased from $1.4 \pm 0.2 \mathrm{~mL} \cdot \mathrm{min}^{-1} \cdot \mathrm{kg}^{-1}$ to a value of $1.7 \pm 0.2 \mathrm{~mL} \cdot \mathrm{min}^{-1} \cdot \mathrm{kg}^{-1}(P=0.002)$. In contrast, the hepatic vein oxygen saturation and the $\mathrm{ERO}_{2}$ were unchanged throughout the infusion period (Figures 3C and 3D).

\section{Discussion}

Using an in vivo rabbit model, we have demonstrated that, although propofol increases $\mathrm{hVO}_{2}$, it preserves the hepatic oxygen balance by improving PvBF and $\mathrm{hDO}_{2}$. Increased PvBF occurred despite systemic hypotension caused by propofol. ${ }^{4}$

\section{Effect of propofol infusion on hepatic blood flow}

Total hepatic blood flow consists of PvBF and HaBF. In our rabbit model, propofol increased $\mathrm{HBF}$, primarily by increasing PvBF, with little effect on $\mathrm{HaBF}$ (Figure 2). Studies in rat models have demonstrated that propofol increased HBF; however, this was due to an increase in both $\mathrm{HaBF}$ and PvBF. ${ }^{4}$ In contrast, studies in dogs established that propofol had no effect on $\mathrm{HBF}, \mathrm{HaBF}$, or PvBF. ${ }^{5,8}$ As a final point, other animal studies have reported a reduction in hepatic blood flow ${ }^{3,6,7}$ A number of explanations for these discrepancies are feasible: differences in drug dos- 
ing; experimental design; and interspecies, propofol, metabolite profiles, ${ }^{13}$ to name a few. However, chief amongst these explanations is the method used to measure blood flow. We employed electromagnetic flowmetry, which is based on Faraday's law, whereby an electromotive force (voltage) is induced whenever a conductor passes through a magnetic field. We recognize that there are several limitations related to the electromagnetic technique. For instance, the relative movement between the probe and the blood vessel may give rise to errors, and, being sensitive to baseline shift, the calibration and the probes require frequent recalibration. In order to fit snugly without constriction and flow turbulence, the probe's diameter must be $5-10 \%$ less than the diameter of the vessel. Despite these limitations, with appropriate precautions, electromagnetic flowmeters provide an accurate measure of blood flow. ${ }^{9,11}$ Studies measuring blood flow, using indirect methods such as indictor dye clearance ${ }^{3,6,7}$ or radio labelled microspheres, ${ }^{4,5}$ are susceptible to experimental error, and their calculations require numerous assumptions..$^{7,9-11}$

One common finding is the apparent inhibition of the hepatic arterial buffer response. ${ }^{14}$ Under normal circumstances, any changes in PvBF are compensated by changes to $\mathrm{HaBF}$, and this response appears to be blunted or blocked by propofol infusion.

\section{Effect of propofol infusion on hepatic oxygen balance}

In the current study, propofol significantly increased $\mathrm{hVO}_{2}$; however, because of the increase in oxygen supply via the portal venous system, hepatic venous saturation and $\mathrm{ERO}_{2}$ remained unchanged. Similar findings were also reported by Carmichael et al.; however, this compensation for an increase in oxygen utilization, due to altered hepatic metabolism secondary to propofol, has not been consistently reported using other experimental models. This is due, in part, to less reliable measurement of blood flow, but also because of other differences in experimental design. For example, in two previous studies, an epidural technique was used for part of the clinical management, which may have had significant effect on $\mathrm{HaBF}$ or $\mathrm{HBF}{ }^{15,16}$ It is important, therefore, to interpret the results of this study while bearing in mind that many anesthetics, or anesthetic techniques, can have a profound effect on hepatic blood flow.

The effect of propofol on $\mathrm{hDO}_{2} / \mathrm{hVO}_{2}$ and blood flow is time-dependent and, presumably, dose dependent, and this is supported by evidence from other experimental models. ${ }^{4}$ Increasing plasma propofol concentrations may explain this finding, as previous studies confirm that the blood concentration of propofol increased with time when administrated by constant infusion. ${ }^{3,17}$

It is important to note that, while in vitro studies have found intralipid to increase $\mathrm{hVO}_{2}{ }^{18}$ it had no effect on oxygen consumption in our in vivo rabbit model, a finding supported by Doursout et al. ${ }^{8} \mathrm{We}$ showed that intralipid had no effect on $\mathrm{HaBF}$ or PvBF.

\section{Study limitations}

The animals were anesthetized with ketamine and sodium pentobarbital. While ketamine has little or no effect on hepatic circulation, ${ }^{19}$ an effect on hepatic metabolism and blood flow cannot be discounted. In addition, sodium pentobarbital is metabolized in the liver and may affect hepatic blood flow and oxygen balance. However, both groups received the same anesthetic and, therefore, differences in hepatic blood flow and oxygen balance can reasonably be attributed to the propofol infusion.

Another limitation of this study was the use of a single infusion rate of $0.6 \mathrm{mg} \cdot \mathrm{kg}^{-1} \cdot \mathrm{min}^{-1}$ over $60 \mathrm{~min}$. At other infusion rates, the increased oxygen utilization may not be compensated for by increased blood flow. Further studies will be needed to clarify the effects of propofol on hepatic blood flow and on hepatic oxygen balance, at different infusion rates administered over prolonged periods. The dose-dependent effect of propofol on organ oxygen balance has been reported previously. For instance, in anesthetized baboons, ${ }^{20}$ it was found that different propofol infusion rates had different effects on cerebral oxygenation.

Patients scheduled for hepatobiliary surgery often have liver cirrhosis. Whether our results are applicable in the presence of hepatic cirrhosis is not known; however, experimental models for liver cirrhosis, e.g., carbon tetrachloride-induced, would allow us to explore this question. ${ }^{21}$

\section{Implications and conclusions}

There are potentially important clinical implications from this work. Although propofol infusion could decrease mean arterial pressure and increase $\mathrm{hVO}_{2}$, the results from this study found no adverse effects on hepatic hemodynamics and oxygen balance. Furthermore, our findings suggest that propofol has the potential to exert a protective effect for patients with compromised hepatic perfusion and oxygenation. An in vivo, ischemia-reperfusion model, using hepatic artery cross-clamping, is currently in progress. In conclusion, propofol, infused at $0.6 \mathrm{mg} \cdot \mathrm{kg}^{-1} \cdot \mathrm{min}^{-1}$, increases hepatic oxygen utilization in rabbits, while maintaining hepatic oxygen balance by increasing 
hepatic oxygen supply, primarily through an increase in hepatic PvBF.

\section{Acknowledgements}

We gratefully acknowledge the assistance of Assistant Professor Ludwik Fedorko, Toronto General Hospital, for his critical comments on this article.

\section{References}

1 Fukuda I, Uchibashi $\Upsilon$, Kira M, et al. Effects of propofol on hepatic venous oxygen saturation - a comparison with isoflurane or sevoflurane anesthesia (Japanese). Masui 2005; 54: 736-41.

2 Armbruster K, Noldge-Schomburg GF, Dressler IM, Fittkan AJ, Haberstroh J, Geiger K. The effects of desflurane on splanchnic hemodynamics and oxygenation in the anesthetized pig. Anesth Analg 1997; 84: 271-7.

3 Leslie K, Sessler DI, Bjorksten AR, Moayeri A. Mild hypothermia alters propofol pharmacokinetics and increases the duration of action of atracurium. Anesth Analg 1995; 80: 1007-14.

4 Carmichael FJ, Crawford MW, Khayyam N, Saldivia V. Effect of propofol infusion on splanchnic hemodvnamics and liver oxygen consumption in the rat. A doseresponse study. Anesthesiology 1993; 79: 1051-60.

5 Haberer JP, Audibert G, Sannier CG, Muller C, Laxenaire MC, Hartemann D. Effect of propofol and thiopentone on regional blood flow in brain and peripheral tissues during normoxia and hypoxia in the dog. Clin Physiol 1993; 13: 197-207.

6 Runciman WB, Mather LE, Selby DG. Cardiovascular effects of propofol and of thiopentone anaesthesia in the sheep. Br J Anaesth 1990; 65: 353-9.

7 Lange H, Stephan H, Rieke H, Kellerman M, Sonntag $H$, Bircher J. Hepatic and extrahepatic disposition of propofol in patients undergoing coronary bypass surgery. Br J Anaesth 1990; 64: 563-70.

8 Doursout MF, Joseph PM, Liang XY, Hartley CJ, Chelly $J E$. Role of propofol and its solvent, intralipid, in nitric oxide-induced peripheral vasodilatation in dogs. $\mathrm{Br} \mathrm{J}$ Anaesth 2002; 89: 492-8.

9 Raisis $A L$. Skeletal muscle blood flow in anaesthetized horses. Part I: measurement techniques. Vet Anaesth Analg 2005; 32: 324-30.

10 Leevy CM, Bender J. Physiology of dye extraction by the liver: comparative studies of sulfobromophthalein and indocyanine green. Ann N Y Acad Sci 1963; 111 : 161-76.

11 Chow PK, $\Upsilon u W K$, Soo KC, Chan ST. The measurement of liver blood flow: a review of experimental and clinical methods. J Surg Res 2003; 112: 1-11.
12 Noldge GF, Priebe HJ, Kopp KH, Pelchen T, Riegel W, Geiger $K$. Differences in effects of isoflurane and enflurane on splanchnic oxygenation and hepatic metabolism in the pig. Anesth Analg 1990; 71: 258-67.

13 Simons PJ, Cockshott ID, Douglas EJ, Gordon EA, Knott $S$, Ruane RJ. Species differences in blood profiles, metabolism and excretion of 14C-propofol after intravenous dosing to rat, dog and rabbit. Xenobiotica 1991; 21: 1243-56.

14 Lautt $W W$. Mechanism and role of intrinsic regulation of hepatic arterial blood flow: hepatic arterial buffer response. Am J Physiol 1985; 249: G549-56.

15 Vagts DA, Iber T, Puccini M, et al. The effects of thoracic epidural anesthesia on hepatic perfusion and oxygenation in healthy pigs during general anesthesia and surgical stress. Anesth Analg 2003; 97: 1824-32.

16 Kennedy WF Jr, Everett GB, Cobb LA, Allen GD. Simultaneous systemic and hepatic hemodynamic measurements during high peridural anesthesia in normal man. Anesth Analg 1971; 50: 1069-77.

17 Fan SZ, Yu HY, Chen YL, Liu CC. Propofol concentration monitoring in plasma or whole blood by gas chromatography and high-performance liquid chromatography. Anesth Analg 1995; 81: 175-8.

18 Shimono H, Goromaru T, Kadota $\Upsilon$, Tsurumaru T, Kanmura $Y$. Propofol displays no protective effect against hypoxia/reoxygenation injury in rat liver slices. Anesth Analg 2003; 97: 442-8.

19 Gelman S. General anesthesia and hepatic circulation. Can J Physiol Pharmacol 1987; 65: 1762-79.

20 Van Hemelrijck J, Fitch W, Mattheussen M, Van Aken $H$, Plets C, Lauwers T. Effect of propofol on cerebral circulation and autoregulation in the baboon. Anesth Analg 1990; 71: 49-54.

21 Constandinou C, Henderson N, Iredale JP. Modeling liver fibrosis in rodents. Methods Mol Med 2005; 117: $237-50$.

\section{APPENDIX}

Equations used for calculation of oxygen delivery/consumption

$\mathrm{HBF}\left(\mathrm{mL} \cdot \mathrm{min}^{-1} \mathrm{~kg}^{-1}\right)=\mathrm{HaBF}+\mathrm{PvBF}$

$\mathrm{hDO}_{2}\left(\mathrm{~mL} \cdot \mathrm{min}^{-1} \cdot \mathrm{kg}^{-1}\right)=\mathrm{DhaO}_{2}+\mathrm{DpvO}_{2}$

$\mathrm{DhaO}_{2}\left(\mathrm{~mL} \cdot \mathrm{min}^{-1} \mathrm{~kg}^{-1}\right)=\mathrm{HaBF} \times \mathrm{Hb} \times \mathrm{SaO}_{2} \times 1.34$

$\mathrm{DpvO}_{2}\left(\mathrm{~mL} \cdot \mathrm{min}^{-1} \mathrm{~kg}^{-1}\right)=\mathrm{PvBF} \times \mathrm{Hb} \times \mathrm{SpvO}_{2} \times 1.34$

$\mathrm{hVO}_{2}\left(\mathrm{~mL} \cdot \mathrm{min}^{-1} \mathrm{~kg}^{-1}\right)=\mathrm{hDO}_{2}-\mathrm{HBF} \times \mathrm{Hb} \times \mathrm{ShvO}_{2} \times 1.34$

$\mathrm{ERO}_{2}(\%)=\mathrm{hVO}_{2} \times \mathrm{hDO}_{2}^{-1} \times 100$

$\mathrm{HBF}=$ total hepatic blood flow; $\mathrm{HaBF}=$ hepatic arterial blood flow; $\mathrm{PvBF}=$ portal venous blood flow; $\mathrm{hDO}_{2}=$ total hepatic oxygen delivery; $\mathrm{DhaO}_{2}=$ hepatic arterial oxygen delivery; $\mathrm{Hb}=$ hemoglobin concentration; $\mathrm{SaO}_{2}=$ hemoglobin oxygen saturation in artery; $\mathrm{DpvO}_{2}=$ portal venous oxygen delivery; $\mathrm{SpvO}_{2}=$ hemoglobin oxygen saturation in portal vein; $\mathrm{hVO}_{2}=$ total hepatic oxygen consumption; $\mathrm{ShvO}_{2}=$ hemoglobin oxygen saturation in hepatic vein; $\mathrm{ERO}_{2}=$ hepatic oxygen extraction . 